\title{
Development of Smart Residential Environment Control System
}

\author{
Wei-Ling Hsu, ${ }^{1}$ Hsu-Hung Tsai, ${ }^{2}$ Ming-Ling Yang, ${ }^{3}$ \\ Shu-Chen Lai, ${ }^{2}$ Ming-Chin Ho, ${ }^{3}$ and Yan-Chyuan Shiau ${ }^{3}$ \\ ${ }^{1}$ School of Urban and Environmental Science, Huaiyin Normal University, \\ No. 111, ChangJang West Road, Huai'an City, Jiangsu Province 223300, China \\ ${ }^{2}$ Department of Civil Engineering, Chung Hua University, \\ No. 707, WuFu Road, Section 2, Hsinchu 30012, Taiwan \\ ${ }^{3}$ Department of Architecture and Urban Planning, Chung Hua University, \\ No. 707, WuFu Road, Section 2, Hsinchu 30012, Taiwan \\ (Received April 29, 2021; accepted May 27, 2021; online published July 27, 2021)
}

Keywords: IoT, human comfort conditions, space and environment, smart home devices, Arduino

Today's world places increasing emphasis on comfort within living spaces. The growth in awareness of energy conservation and environmental preservation has gradually contributed to the widespread use of smart home control systems. In this study, data related to human comfort conditions were compiled, and the control of smart devices in home environments was explored. Specifically, information communication technology and the Internet of Things (IoT) were combined to create a smart control system that creates a comfortable, energy-conserving home environment through the concurrent monitoring of both indoor and outdoor environmental data. If the outdoor indicators are ideal (denoting a comfortable environment) but the indoor indicators are not ideal (denoting an uncomfortable environment), the system opens a window to allow the incorporation of favorable outdoor environmental factors into the indoor environment. When the outdoor environment is uncomfortable, the window is closed to prevent the infiltration of unfavorable outdoor environmental factors. When the indoor indicators are nonideal, various types of equipment are activated according to the detection values. For example, when the humidity level is overly high, the dehumidifier is turned on. When the concentration of particulate matter with a diameter of $<2.5 \mu \mathrm{m}$ is overly high, the air purifier is turned on. When the temperature is too high or low, the air conditioner is turned on, and when the $\mathrm{CO}_{2}$ concentration is too high, the fan is turned on for ventilation. The values detected by each sensor and the operating conditions of each device are also displayed on the screen for the reference of the user, who can adjust the threshold values to their preferences.

\section{Introduction}

In recent years, people have become increasingly concerned about the quality of their home living environment, contributing to the current popularity of the topic of home comfort. Advances in relevant technologies have facilitated the realization of physical requirements for

*Corresponding author: e-mail: ycshiau@ms22.hinet.net https://doi.org/10.18494/SAM.2021.3420 
ensuring comfort within home environments. Developments in manufacturing have resulted in the continual exacerbation of environmental pollution, which has produced extreme climate events, smog, and serious climate anomalies, including those caused by the greenhouse effect. ${ }^{(1)}$ Using sensors and smart control mechanisms to optimize the management of indoor air quality and comfort level as part of energy conservation plays a pivotal role in the field of building environment control. The health and productivity of home occupants are closely related to indoor environment quality. ${ }^{(2,3)}$

\subsection{Research content}

A literature review was performed to examine the current applications of the Internet of Things (IoT) and smart buildings in creating a comfortable home living environment. According to a report issued by the United States Department of Energy, buildings account for $41 \%$ of the country's total energy consumption. ${ }^{(4,5)}$ The optimal control of environmental conditions in buildings (e.g., temperature, humidity, and lighting) contributes critically to the quality of the indoor environment and the energy efficiency of buildings. An IoT-based system for controlling the indoor environment typically connects various types of sensors for building environment control through lighting, ventilation, and air conditioning systems, among others. In the present study, with a comfortable home environment as the objective, data were compiled on temperature, humidity, and the concentrations of carbon dioxide $\left(\mathrm{CO}_{2}\right)$ and particulate matter with a diameter of $<2.5 \mu \mathrm{m}\left(\mathrm{PM}_{2.5}\right)$, and the sensing components were linked using an Arduino control panel. ${ }^{(6,7)}$ Finally, software was designed to control the equipment. The study objectives were as follows: (1) compile data on factors determining the comfort of home living that can be controlled by smart systems and their comfortable ranges; (2) explore and utilize IoT sensing components to measure the detected values of each environmental factor; (3) monitor the values through the Arduino control panel and subsequently control relevant equipment using the developed software; and (4) construct a prototype of the system and test its functions.

\subsection{Materials and methods}

Smart buildings often feature the connection of equipment for building environment control (i.e., lighting, ventilation, and air conditioning systems) to various types of sensors for centralized control. Heating, ventilation, and air conditioning (HVAC) systems consume approximately $70 \%$ of the energy used by commercial office buildings. ${ }^{\left({ }^{8}-10\right)}$ Buildings and the equipment within them consume a tremendous amount of energy. This generates pollution constituting of gases such as $\mathrm{CO}_{2}$, sulfur dioxide, and nitrogen dioxide and contributes to global warming. ${ }^{(8,11)}$ Therefore, reducing energy consumption in the building environment is essential. Because it is closely related to the behavior of building personnel, energy conservation can be achieved by controlling equipment operations by using detected values. To understand the behavioral patterns of building occupants, various types of sensors are often used to collect environmental data in smart buildings. ${ }^{(12,13)}$ In this study, a smart home environment control system was developed. The methods used are presented as follows: 


\section{A. Literature review}

Data related to the application of various technologies (e.g., IoT) in the field of home environment control were compiled through a literature review to extract information on the latest technologies for incorporation into the developed system.

\section{B. Exploration of hardware functions in the IoT}

Continual technological innovation has contributed to the progressive development of information and communications technology, in which links between such technology and various objects are enabled. This paradigm of object connection is known as the IoT, ${ }^{(14-16)}$ for which numerous types of sensing components have been developed. System components and control panels must be selected according to specific conditions within an environment. Thus, in the present study, suitable IoT components were determined, their functions were examined, and the wiring and connection between the components and the control panel were investigated.

\section{Program design}

On the basis of specific scenarios, a program was developed to monitor and collect the data detected by the sensing components. When the monitored data reach preset values, the operations of the controllable devices can be initiated or shut down to maximize environmental comfort.

\section{Testing}

For any smart system to operate according to its functions, it must be subjected to a series of tests to verify its precision. In this study, we assessed environmental data such as indoor and outdoor temperature, humidity, and $\mathrm{CO}_{2}$ and $\mathrm{PM}_{2.5}$ concentrations, according to which the operations of air conditioners, dehumidifiers, air purifiers, and fans were controlled, as were the opening and closing of windows in specific scenarios.

\section{Literature Review}

\subsection{Smart buildings}

Smart building operations, including automatic sensing and analysis, are realized through Internet technology, monitoring equipment, and system integration. At the initial stage of planning and design, user needs should be highlighted, and the convenience of subsequent maintenance and management must be considered. This enables the fulfillment of user needs, such as safety, comfort, convenience, and efficiency, through the operation of an optimized combination of components. Furthermore, energy conservation and management/maintenance cost reduction can also be achieved. The health and productivity of indoor space occupants are dependent on indoor environmental quality (IEQ). ${ }^{(17-20)}$ Information on particulates in building environments facilitates improvements in energy conservation, thermal comfort, and air quality within buildings. ${ }^{(21-23)}$ To allow better understanding of the quality of the thermal environment in the living space, as well as occupants' perception of IEQ, through which health and 
productivity can be enhanced, equipment such as thermostats, smart meters, $\mathrm{CO}_{2}$ sensors, and heart rate sensors ${ }^{(24-26)}$ can be used. In addition, analyzing building occupants' behavioral patterns by using sensors is conducive to energy conservation. ${ }^{(10,27)}$

In our previous research, we established a smart living control system, in which a temperature and humidity sensor, air quality sensor, and gas sensor were used to obtain the indoor physical environment index. An environmental control system for a smart household has been established through Arduino in that study to provide a low-cost and highly smart environmental monitoring and sensing system. ${ }^{(23)}$

\subsection{Conditions of comfortable smart home environments}

Home occupants' health is related to indoor temperature and humidity. Overly high temperatures result in emotional agitation and restlessness, whereas overly low temperatures can trigger headaches and contribute to illnesses such as fever and influenza. Ideally, RT should be between 18 and $20{ }^{\circ} \mathrm{C}$. Indoor humidity, which plays a crucial role in maintaining the normal function of the respiratory tract, is best maintained between 40 and $50 \%$. Indoor air should be kept fresh; this can be achieved by frequent ventilation and air exchange. Fresh air contains a large amount of anions, which regulate cortical function, reduce fatigue, boost work efficiency, improve immune system function, and enhance immunity. The most appropriate time periods to open windows for ventilation are 9-11 a.m. and 2-4 p.m.

A. Indoor air quality standards

According to the indoor air quality standards established by the Taiwan Environmental Protection Administration ${ }^{(28)}$ in 2012, we have collected data related to nine indicators of indoor air quality in this study (Table 1).

B. Human perception of temperature and humidity

In meteorology, humidity often refers to air humidity - that is, the content of water vapor in the air. Liquid or solid water in the atmosphere does not count toward humidity. The American

Table 1

Indoor air quality standards.

\begin{tabular}{|c|c|c|c|}
\hline Item & & Standard value & Unit \\
\hline $\mathrm{CO}_{2}$ & $8 \mathrm{~h}$ value & 1000 & ppm \\
\hline $\mathrm{CO}$ & $8 \mathrm{~h}$ value & 9 & ppm \\
\hline $\mathrm{HCHO}$ & $1 \mathrm{~h}$ value & 0.08 & ppm \\
\hline $\begin{array}{l}\text { Total volatile organic compounds } \\
\text { (sum of } 12 \text { types of volatile } \\
\text { organic compounds) }\end{array}$ & $1 \mathrm{~h}$ value & 0.56 & ppm \\
\hline Bacteria & $\begin{array}{l}\text { Maximum } \\
\text { value }\end{array}$ & 1500 & $\mathrm{CFU} / \mathrm{m}^{3}$ \\
\hline Fungi & $\begin{array}{l}\text { Maximum } \\
\text { value }\end{array}$ & $\begin{array}{l}\text { 1000. However, indoor-outdoor fungal } \\
\text { concentrations } \leq 1.3 \text { are not limited by this value. }\end{array}$ & $\mathrm{CFU} / \mathrm{m}^{3}$ \\
\hline $\mathrm{PM}_{10}$ & $24 \mathrm{~h}$ value & 75 & $\mu \mathrm{g} / \mathrm{m}^{3}$ \\
\hline $\mathrm{PM}_{2.5}$ & $24 \mathrm{~h}$ value & 35 & $\mu \mathrm{g} / \mathrm{m}^{3}$ \\
\hline $\mathrm{O}_{3}$ & $8 \mathrm{~h}$ value & 0.06 & $\mathrm{ppm}$ \\
\hline
\end{tabular}


Society of Heating, Refrigerating and Air-Conditioning Engineers recommended that humidity levels be maintained between 30 and $60 \%$; levels outside this range negatively affect health and comfort. Humidity affects not only occupants' health but also the quality of the home environment. ${ }^{(29)}$ For example, personal items can often be damaged by high levels of humidity. However, given that this damage occurs relatively slowly, the impact of humidity is often overlooked. When humidity is high, fungi appear, potentially destroying artwork, clothes, books, furniture, and towels. Thus, the influence of humidity on health and comfort is clear. Although RT preferences vary among individuals, most people feel uncomfortable in humid environments. On the other end of the spectrum, an environment with overly low humidity can result in the sensations of dryness, as well as allergic reactions and disease.

Somatosensation is not affected by temperature and humidity independently; instead, it is affected by a combination of both these factors. Experimental evidence indicates that the most pleasant indoor temperature and humidity level (for more than $95 \%$ of individuals) in winter are $18-25^{\circ} \mathrm{C}$ and $30-80 \%$, respectively. In summer, they are $23-28^{\circ} \mathrm{C}$ and $30-60 \%$, respectively. In an air-conditioned indoor environment, the most pleasant indoor temperature and humidity level are $19-24{ }^{\circ} \mathrm{C}$ and $40-50 \%$, respectively. Most people feel comfortable under these conditions. Considering the impacts of temperature and humidity on mental activities, the most suitable temperature and humidity level are $18{ }^{\circ} \mathrm{C}$ and $40-60 \%$, respectively. Specifically, under such conditions, mental activity, including mental agility and work efficiency, is optimal (Table 2).

In theory, ideally, indoor humidity can be kept below $60 \%$. However, Taiwan has an island climate, and the humidity is generally higher than $80 \%$. To maintain humidity below $60 \%$, we need to have good airtight facilities; otherwise, the dehumidifier will operate for a long time, which is very energy-intensive. To achieve a comfortable environment and effective and energysaving use of dehumidifiers, we set the target humidity at $70 \%$. That is, when the indoor humidity is higher than $70 \%$, the dehumidifier is started, and when the humidity is lower than $70 \%$, the dehumidifier is turned off.

\subsection{IoT}

The IoT refers to the connections between an omnipresent terminal device with other devices such as smart sensors, smart equipment, and industrial equipment. ${ }^{(30-33)}$ A growing number of products are adopting the IoT paradigm. Users can lead smart lives by turning hardware such as air conditioners or lights on and off with a touch on their smartphone. The diverse applications of the IoT, combined with the availability of numerous low-cost digital production and development tools, have propelled the concept of the IoT onto the path of commoditization and

Table 2

Influence of relative humidity on health.

\begin{tabular}{lccc}
\hline Overall humidity & Lower than $30 \%$ & $30-60 \%$ & Higher than $60 \%$ \\
\cline { 2 - 2 } Impact & Eye dryness and nasal congestion & & Accelerated fungal growth \\
\cline { 2 - 2 } & Aggravated allergic symptoms & Comfortable & $\begin{array}{c}\text { Proliferation of dust mites, } \\
\text { bacteria, and fungi }\end{array}$ \\
\cline { 2 - 2 } & $\begin{array}{c}\text { Enhanced probability of } \\
\text { survival of certain viruses }\end{array}$ & & $\begin{array}{c}\text { Failure of perspiration } \\
\text { to lower body temperature }\end{array}$ \\
\hline
\end{tabular}


commercialization. Software applications such as Arduino and Webduino can now be opened from web pages on both Windows and Mac computers and on devices with Android and iOS operating systems alike, allowing the operation of electronic components and the transmission of sensor data. In short, the IoT enables the simple realization of cross-platform control.

In the IoT, objects are connected to the Internet and monitored through frequency identification information. ${ }^{(30)}$ The IoT is regarded as an expansion of Internet applications and innovation with the user experience at its core.

\section{Research Design}

\subsection{Hardware and software}

\section{A. Arduino}

Arduino, ${ }^{(6)}$ an open-source interactive environment development technology, can mainly be divided into three categories, namely, hardware, software, and extension components. As shown in Fig. 1, the hardware primarily consists of ready-made circuit boards. The software development environment features open-source codes, and the grammar of the programming language used by Arduino is similar to that of $\mathrm{C}$ or $\mathrm{C}^{++}$. The software, which features a text editing interface, a bar presenting frequently used tools, a graphic control interface, and an error editor, is used for the program uploads and sensor communication. The console interface keeps a complete log of the execution information, and the input/output values can be monitored using this interface. Built on the basis of a simple input/output interface, Arduino provides a development environment similar to that in Java and C. The circuit boards comprise various types of microprocessors and controllers and are typically equipped with a set of digital and analog input/output pins, which can be used to connect to various expansion boards and breadboards or other circuits. Furthermore, these circuit boards usually feature serial ports (including USB ports on some models), and are thus used in PC loaders.

\section{B. Raindrop sensor}

The raindrop sensor module (Fig. 2) mainly detects drops of water by using the wiring on the metal surface. Therefore, the higher the water content, the larger the conductive area. From the changes in the measured values, the subsequent operations can be decided.

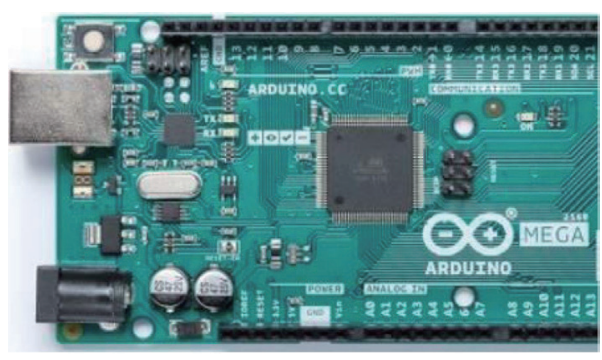

Fig. 1. (Color online) Arduino Mega microcontroller board.

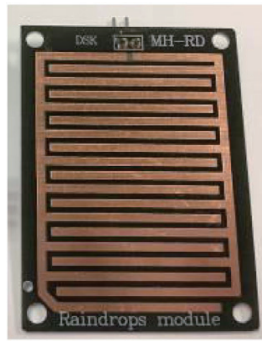

Fig. 2. (Color online) Arduino raindrop sensor. 


\section{Dust sensor}

The dust sensor (GP2Y1014AU0F) used in the present study is an optical device that detects dust particles in the air. Within its interior is a diagonal arrangement of an IR LED and a phototransistor, which allow the sensor to detect the light reflected by the dust in the air. Even minute particles such as tobacco smoke particulates can be detected by this sensor (Fig. 3). The dust sensor has a relatively low current consumption and its analog voltage output is proportional to the dust concentration.

\section{IR emitter}

Visible light has wavelengths of 390-700 nm. In particular, the wavelength of visible red light is approximately $620-750 \mathrm{~nm}$. Electronic appliances that are remotely controlled, such as televisions and air conditioners, typically use IR light of $940 \mathrm{~nm}$ to prevent disturbances by the IR light emitted by the sun or indoor fixtures. Given that various objects can emit IR light, IR receivers are designed to respond only to specific frequencies, most commonly $38 \mathrm{kHz}$. IR LEDs, which emit IR light of specific wavelengths, can transform electrical energy into near-IR (invisible) light; therefore, they constitute a light-emitting component. IR LEDs are mainly used in photoelectric switches and remote control transmitters or receivers. ${ }^{(34)}$ The IR LED in Fig. 4 was used to control the operation of the remote control appliances in the current study.

\section{E. Carbon monoxide (CO) sensor}

The gas-sensitive material used by the MQ-7 CO gas sensor ${ }^{(35)}$ (Fig. 5) is tin oxide, which has a lower rate of electrical conductivity in clean air. The MQ-7 sensor uses a low-high temperature cycling method to detect $\mathrm{CO}$ under a low-temperature $(1.5 \mathrm{~V})$ heating condition. The electricity conductance rate of the sensor increases with the $\mathrm{CO}$ concentration in the air. High-temperature $(5 \mathrm{~V})$ heating is used to detect stray gases absorbed under the low-temperature condition. By using a simple circuit, changes in the electricity conductance rate can then be transformed into an output signal corresponding to the current gas concentration. This sensor has a high sensitivity toward $\mathrm{CO}$ and can detect various gases that contain $\mathrm{CO}$.

\section{F. $\mathrm{CO}_{2}$ sensor}

The MG811 $\mathrm{CO}_{2}$ sensor ${ }^{(36)}$ can be used in home environments to detect concentrations between 0 and 10000 ppm (Fig. 6).

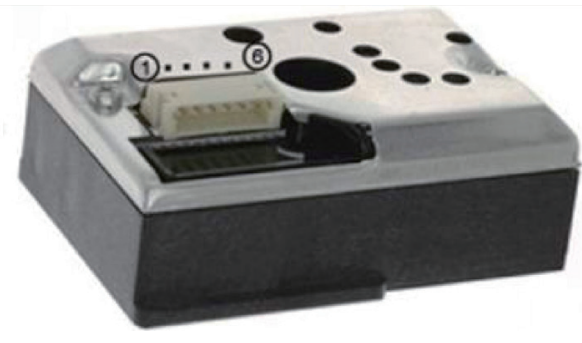

Fig. 3. (Color online) Optical dust sensor.

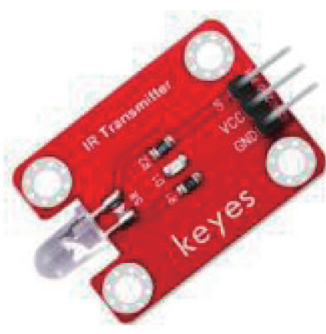

Fig. 4. (Color online) IR emitter. 


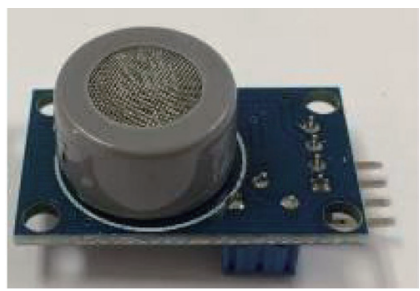

Fig. 5. (Color online) MQ-7 CO gas sensor.

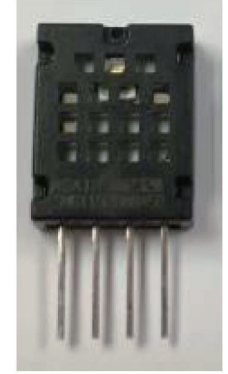

Fig. 7. (Color online) AM2320 sensor.

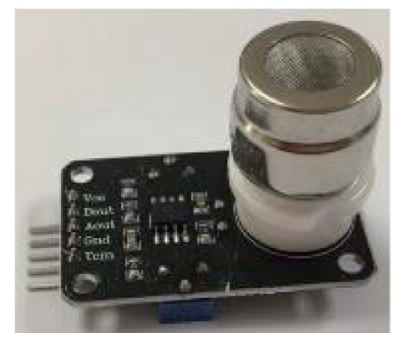

Fig. 6. (Color online) $\mathrm{MG} 811 \mathrm{CO}_{2}$ gas sensor.

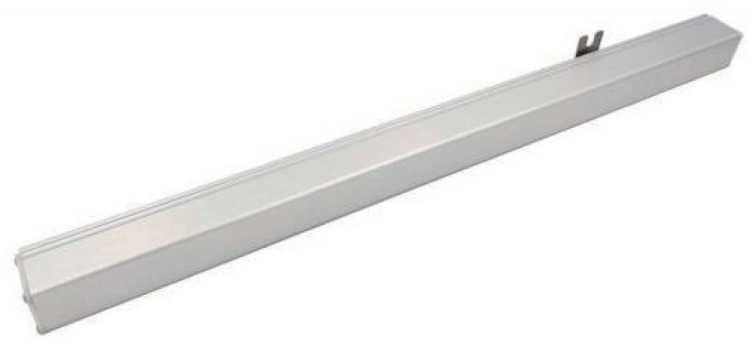

Fig. 8. (Color online) Electronic window opener.

\section{G. Temperature and humidity sensor}

The outputs of the AM2320 digital temperature and humidity sensor (Fig. 7) ${ }^{(37)}$ are generated through self-calibrated digital signals. This sensor is highly reliable with long-term stability owing to the special technology used for temperature/humidity detection. The sensor, which has an extremely fast response and strong anti-interference ability, consists of a capacitance-type humidity component and an integrated high-precision temperature measurement device connected to a high-performance microprocessor.

\section{H. Thin-film transistor (TFT) monitor}

The 3.5-inch TFT color liquid crystal display (LCD) display module is a $320 \times 480$ ultrahighdefinition LCD screen that supports development boards such as Arduino UNO, Arduino Mega 2560, and Arduino Due. The monitor, which can be plugged in and connected to the control panel without any additional wiring, is used to display larger quantities of information in the Arduino system - in this study, the values of the environmental factors and the operational conditions of the appliances.

\subsection{Smart environment control mechanisms}

\section{A. Electronic window opener}

When a window must be opened or closed, the developed system prompts the KST-SL02 electronic window opener (Fig. 8) to do so through an electronic relay. This system is typically installed at the base of a horizontal sliding window. Its use in conjunction with wheel sets installed at the base of this window ensures the smoothness of the window opening operation. 
This product adopts a DC motor design. Therefore, it must be used in concert with an exclusive control box to achieve the various automatized window opening functions. In this study, the control signals were transmitted to the electronic window opener through the control panel, such that the system could automatically control window opening or closing as necessary. The electronic window opener can enhance the usage rate of transom windows, promote natural indoor ventilation, and reduce dependence on air conditioning for temperature control.

\section{B. Electronic relay}

Relays (Fig. 9), a type of electronic switch containing both a control system and a controlled system, are often used in the automatic control of electronic circuits. Relays use a smaller current to control a larger current. In circuits, relays serve as automatic regulators, with other functions of safety protection and circuit transformation. In this study, a relay was used to open and close the window.

\section{Air conditioner}

When physical air exchange and temperature reduction methods fail to meet indoor comfort needs in the present study, the temperature was lowered by switching on an air conditioner. Air conditioners rapidly increase or decrease RT through heat exchange with coolants, facilitating increased comfort within a short period of time.

\section{Dehumidifier}

The subtropical oceanic climate of Taiwan often results in high temperatures and high humidity. In the present study, when the indoor humidity was too high, the dehumidifier was used to lower it and thereby contribute to a comfortable environment.

\section{E. Air purifier}

When the indoor air quality is nonideal, other than opening the window to promote air exchange, an air purifier can also be used to filter out $\mathrm{PM}_{2.5}$. Furthermore, these appliances can capture $99.9 \%$ of the allergens and germs in the air, effectively removing any unpleasant odors.

\section{F. Servomotor}

Servomotors are a component often used in toys, mechanical arms, and robots. In general, servomotors can rotate by $180^{\circ}$, and they can be precisely controlled through pulse-width modulation. In this study, the servomotor (Fig. 10) was attached to the dehumidifier and used to switch it on and off. This was achieved by rotating the servomotor and touching the switch.

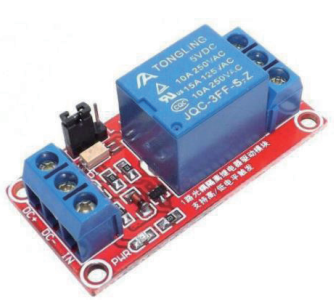

Fig. 9. (Color online) Relay.

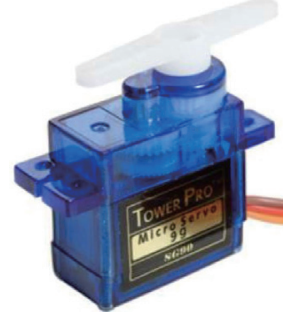

Fig. 10. (Color online) Servomotor. 
G. Fan

The L9110 fan (Fig. 11) can rotate clockwise or anticlockwise. When the indoor $\mathrm{CO}_{2}$ concentration is overly high, the fan can be turned on for ventilation and air exchange.

\section{H. Smart power outlet}

A smart power outlet (Fig. 12) was used to control the air purifier.

\subsection{Ideal indoor and outdoor environmental conditions and the corresponding strategies}

We made appropriate judgments regarding the quality of the home environment by using the criteria listed in Table 3. In actual applications, these values can be adjusted according to personal needs.

In the current study, regardless of whether the environment was indoors or outdoors, it was considered comfortable if the detected values fell within the ranges of comfort. If any value fell within a range of discomfort, the environment was considered uncomfortable.

The operational logic conditions of the appliances controlled in this study are as follows:

A. If the outdoor environment is comfortable and the indoor environment is not comfortable, then the window is opened. Through natural ventilation, the indoor temperature, humidity, $\mathrm{CO}_{2}$ concentration, etc., can be changed over a period of time to make the indoor environment comfortable.

B. When the outdoor environment is within the uncomfortable range, the window is opened and the following monitored values are assessed and acted on accordingly:

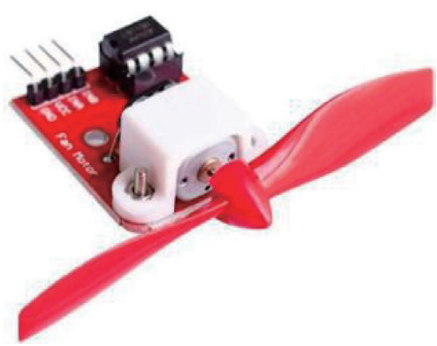

Fig. 11. (Color online) Fan.

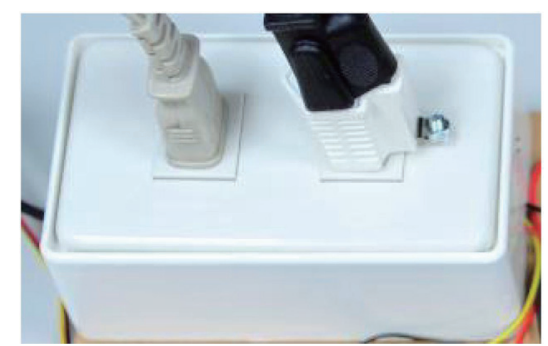

Fig. 12. (Color online) Smart power outlet.

Table 3

Quality assurance of the ideal home environment.

\begin{tabular}{lcc}
\hline Item & Comfortable range & Range of discomfort \\
\hline Temperature & $19-24^{\circ} \mathrm{C}$ & $<19^{\circ} \mathrm{C}$ or $>25^{\circ} \mathrm{C}$ \\
Humidity & $30-60 \%$ & $<30 \%$ or $>60 \%$ \\
Rain drop sensor & Dry & Humid \\
$\mathrm{CO}_{2}$ & $8 \mathrm{~h}$ value $\leq 1000 \mathrm{ppm}$ & $8 \mathrm{~h}$ value $>1000 \mathrm{ppm}$ \\
$\mathrm{CO}$ & $8 \mathrm{~h}$ value $\leq 9 \mathrm{ppm}$ & $8 \mathrm{~h}$ value $>9 \mathrm{ppm}$ \\
$\mathrm{PM}_{10}$ & $24 \mathrm{~h}$ value $\leq 75 \mu \mathrm{g} / \mathrm{m}^{3}$ & $24 \mathrm{~h}$ value $>75 \mu \mathrm{g} / \mathrm{m}^{3}$ \\
$\mathrm{PM}_{2.5}$ & $24 \mathrm{~h}$ value $\leq 35 \mu \mathrm{g} / \mathrm{m}^{3}$ & $24 \mathrm{~h}$ value $>35 \mu \mathrm{g} / \mathrm{m}^{3}$ \\
\hline
\end{tabular}


(1) When the temperature is overly high or low, the air conditioner is turned on.

(2) When the $\mathrm{CO}_{2}$ concentration is overly high, the fan is turned on to enable air exchange.

(3) When the $\mathrm{PM}_{2.5}$ or $\mathrm{PM}_{10}$ concentration is overly high, the air purifier is turned on.

(4) When the level of humidity is overly high, the dehumidifier is turned on.

(5) When the indoor sensor indicates that the monitored values have returned to the comfortable range, the appliances are switched off.

C. When the CO concentration is too high, it is lowered by opening the window and turning on the fan to promote forced ventilation.

\section{Results}

\subsection{Study results}

On the basis of the architecture framework presented in Fig. 13, the smart home environment control system was constructed. The upper panels of the figure present the sensors used to collect the environmental parameters. The left, center, and right images in the center panel of the figure depict the display, the control panel, and the program editing interface, respectively. Finally, the bottom panel of the figure presents the appliances within the system. Figure 14 presents the system prototype and Fig. 15 depicts the system in operation.

As shown in Fig. 16, an LCD monitor was used to display the following: (1) relevant values detected by the indoor and outdoor sensors (e.g., $\mathrm{CO}$ concentration, $\mathrm{PM}_{2.5}$ concentration, indoor $\mathrm{CO}_{2}$ concentration, humidity, temperature, and whether it is raining); (2) whether the indoor or outdoor environment was comfortable; and (3) the operating conditions of each control component.

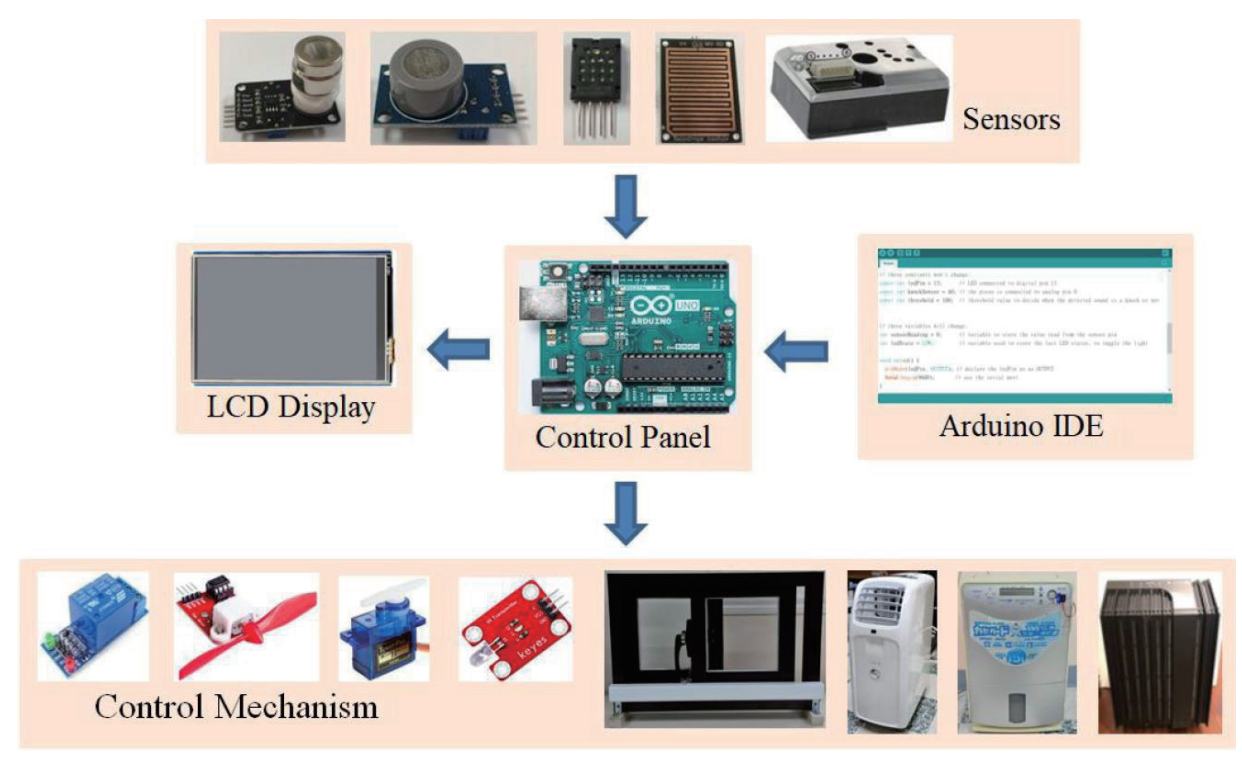

Fig. 13. (Color online) Architecture of the smart home environment control system. 


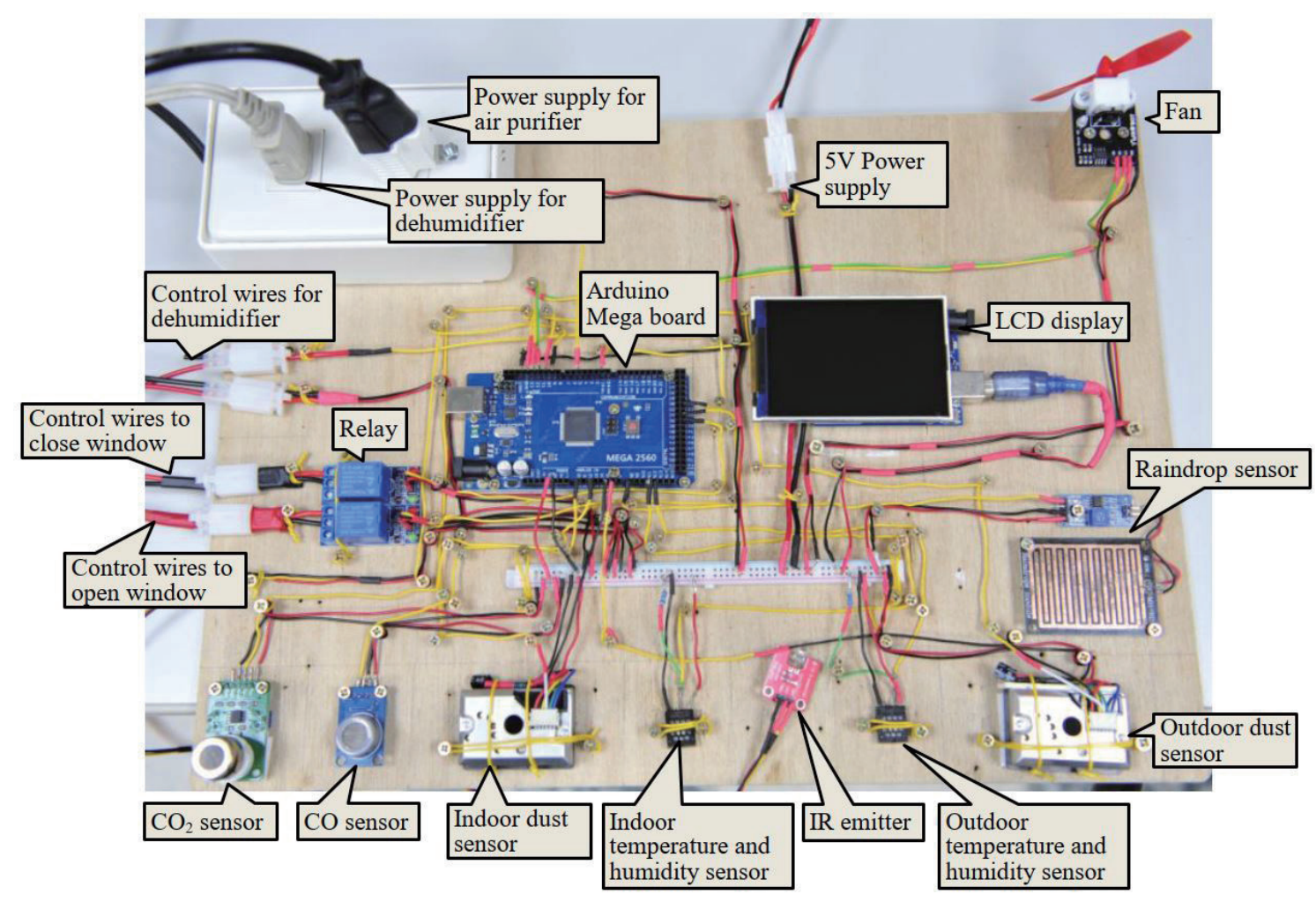

Fig. 14. (Color online) Prototype of the smart home environment control system.

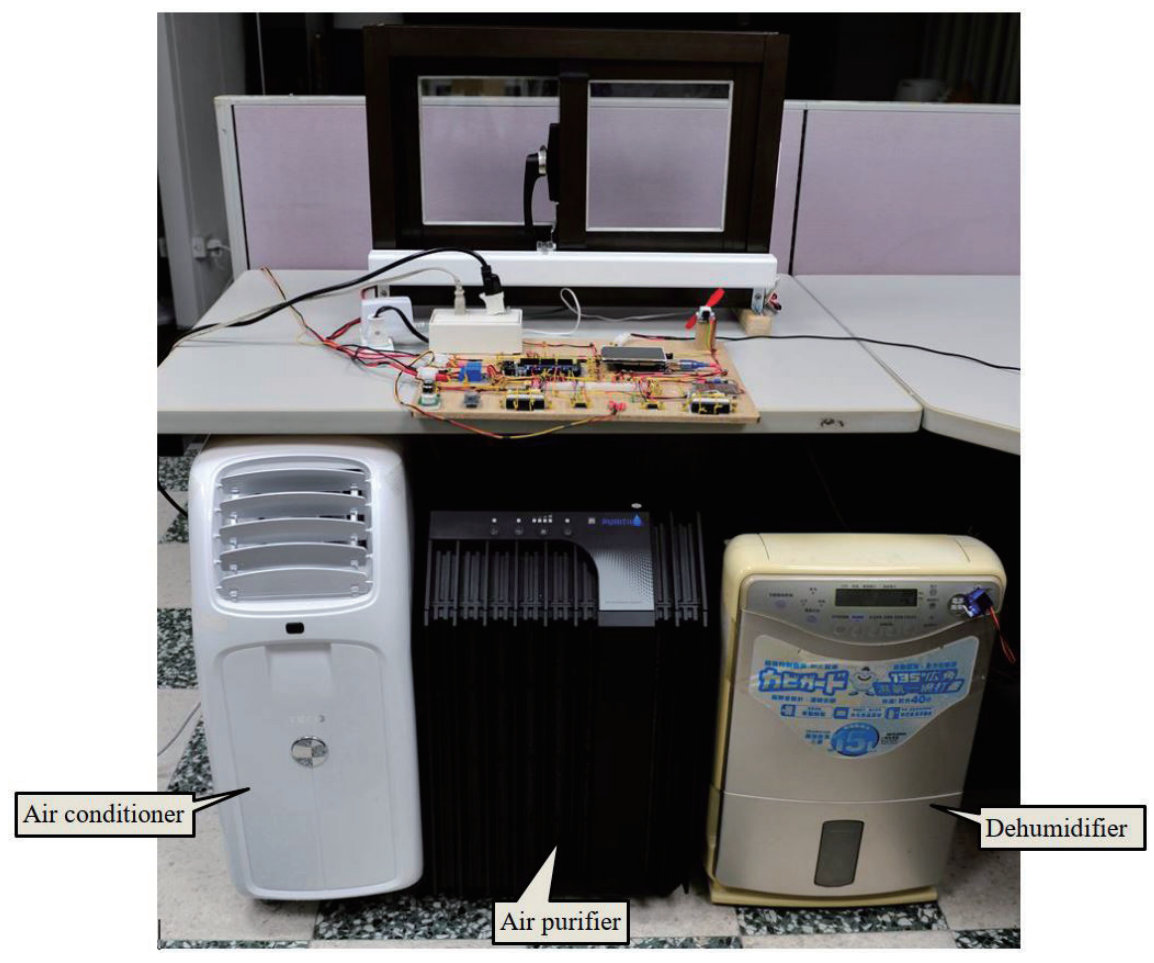

Fig. 15. (Color online) Smart home environment control system in operation. 


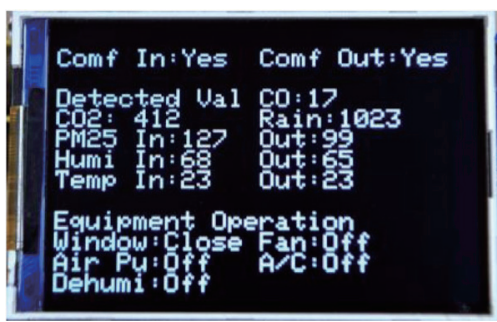

(a)

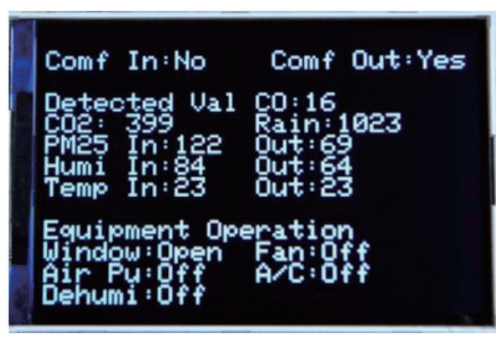

(d)

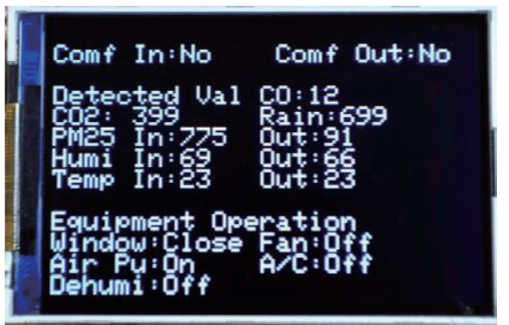

(g)

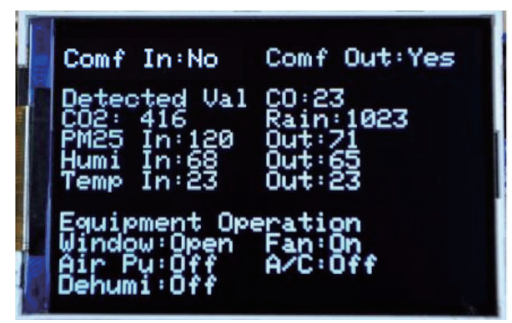

(b)

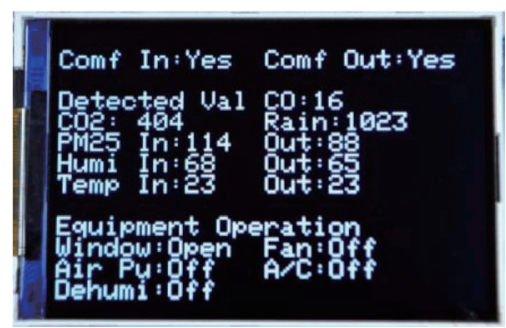

(e)

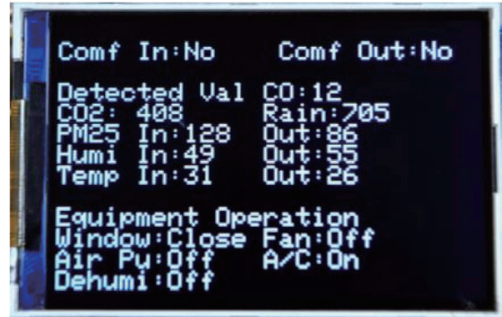

(h)

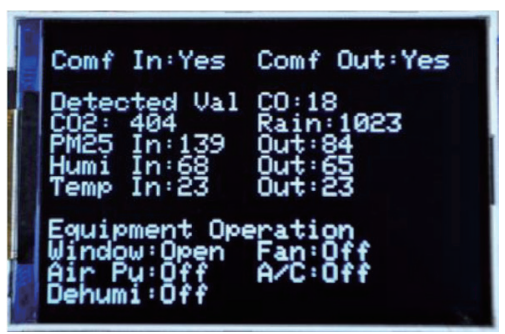

(c)

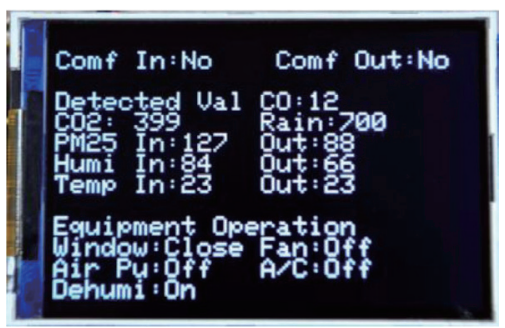

(f)

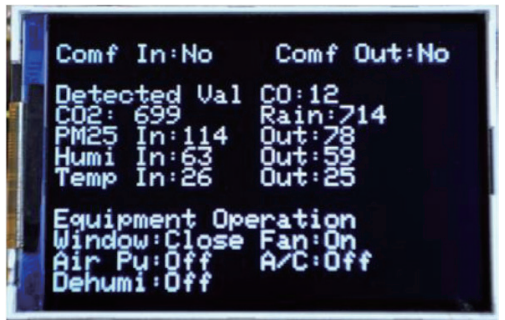

(i)

Fig. 16. (Color online) Displays of the system in operation. (a) Outdoor and indoor environments both comfortable. (b) High CO concentration, windows open, and fan turned on for ventilation. (c) Fan turned off when CO concentration returns to normal. (d) High humidity, windows open for ventilation. (e) Indoor humidity has dropped. (f) Outdoor rainy, windows closed, high humidity indoors, and dehumidifier turned on. (g) Outdoor rainy, windows closed, $\mathrm{PM}_{2.5}$ concentration too high, and air purifier turned on. (h) Outdoor rainy, windows closed, high temperature indoors, and air conditioner turned on. (i) Outdoor rainy, windows closed, indoor $\mathrm{CO}_{2}$ concentration too high, and fan turned on for ventilation.

The raindrop sensor used in this study has a specific way of expressing its detection value. When no rain is detected, the value read from the sensor is about 1023. However, when there are raindrops, the detection value drops to about 700 . The threshold value set in this study is 950 . When the detection value is higher than 950, it is not raining, and when the detection value is lower than 950, it is raining.

Figure 16(a) shows the display when the values detected by the indoor and outdoor sensors are in an ideal range, indicating a comfortable environment both indoors and outdoors. When the CO concentration became too high [Fig. 16(b)], the windows opened (Fig. 17) and the fan was turned on [Fig. 18(b)] to improve ventilation. This caused the CO concentration to decrease, 


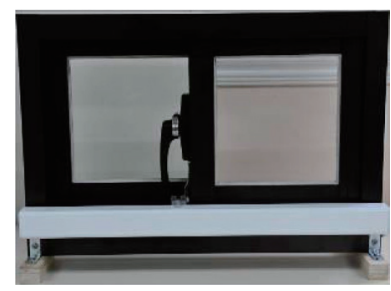

(a)

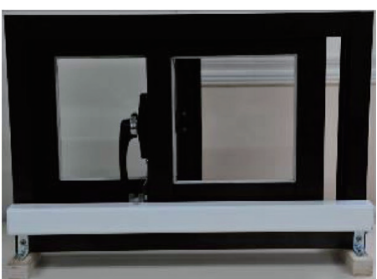

(b)

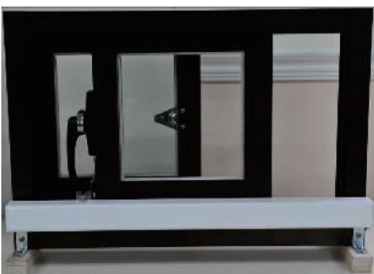

(c)

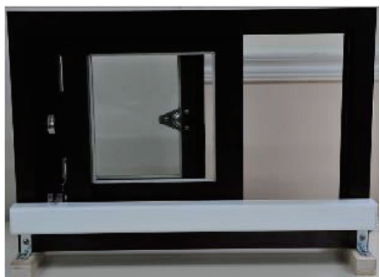

(d)

Fig. 17. (Color online) Images depicting window opening by the automatic window opener. (a) Window closed. (b) Window opening. (c) Window almost completely open. (d) Completely opened window.

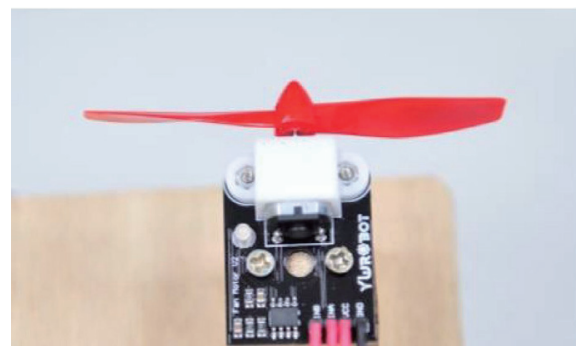

(a)

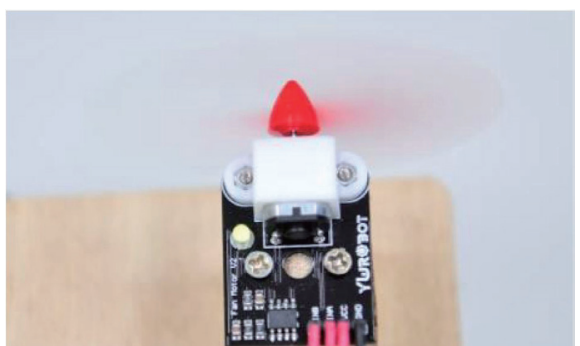

(b)

Fig. 18. (Color online) Images depicting the operation of the fan. (a) Fan in off mode. (b) Fan in on mode.

and the fan turned off when the CO concentration reached an ideal value [Fig. 16(c)]. Next we observed the operation of the system when the outdoor environment was comfortable but the indoor environment was uncomfortable due to high humidity, which caused the system to open the window to improve the ventilation [Fig. 16(d)]. This caused the humidity to decrease and the indoor environment to become comfortable [Fig. 16(e)]. Figure 16(f) shows the display when the raindrop sensor detected that it was raining outdoors, i.e., the outdoor environment was uncomfortable. At this time, the windows were automatically closed to isolate the uncomfortable outdoor environment. At the same time, when high humidity was detected in the room, the dehumidifier was activated (Fig. 19) to reduce the humidity. When it rained outdoors and the indoor $\mathrm{PM}_{2.5}$ was too high [Fig. 16(g)], the air purifier was activated (Fig. 20) to clean the air and improve the air quality. Figure 16(h) shows the display when it was raining outside and the indoor temperature was too high. The air conditioner was activated to lower the temperature (Fig. 21). When the outdoor environment was uncomfortable and the indoor $\mathrm{CO}_{2}$ concentration was too high, the fan was activated to provide ventilation [Fig. 16(i)].

\subsection{Novelty of this study}

Our novel system uses indoor and outdoor sensors to detect indoor and outdoor environment conditions. When the indoor environmental conditions are uncomfortable, the outdoor environmental conditions are first determined, then the countermeasures to take are decided. If 


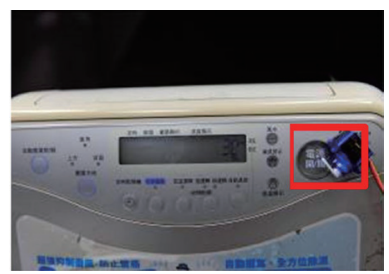

(a)

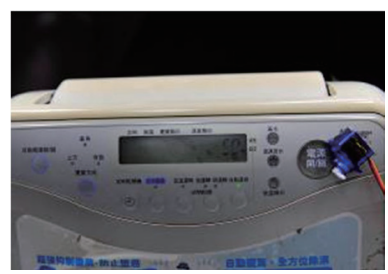

(b)

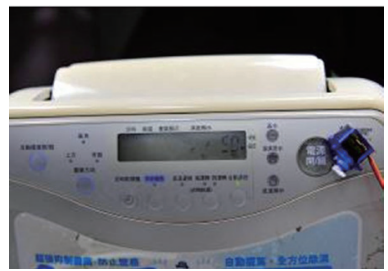

(c)

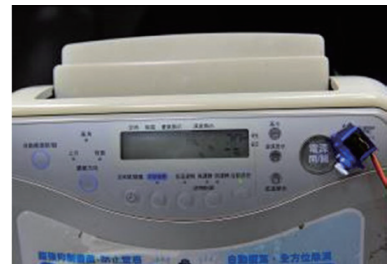

(d)

Fig. 19. (Color online) Images depicting the dehumidifier being turned on using the servomotor. (a) Dehumidifier in off mode. The air outlet is completely closed. The servomotor has a swing rocker to touch the switch of the dehumidifier to start the operation. (b) Dehumidifier being switched on. The air outlet starts to open. (c) Dehumidifier when switching on process is almost completed. (d) Dehumidifier in on mode. The air outlet is fully open.

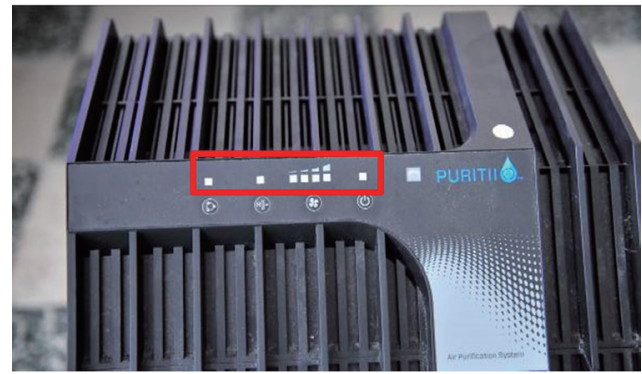

(a)

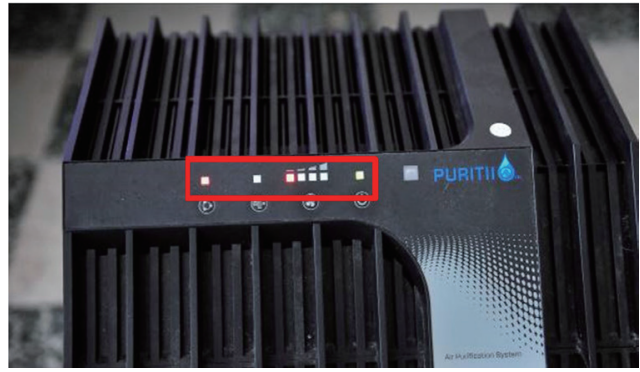

(b)

Fig. 20. (Color online) Images depicting the operation of the air purifier. (a) Air purifier in off mode (lights are off). (b) Air purifier in on mode (lights are on).

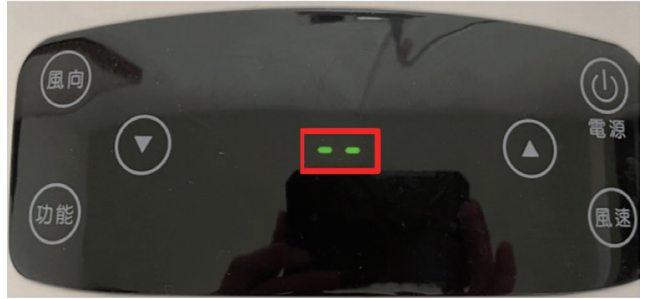

(a)

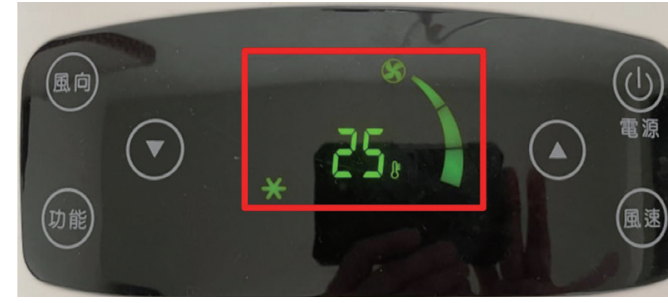

(b)

Fig. 21. (Color online) Images depicting the operation of the air conditioner. (a) Air conditioner in off mode (off pattern). (b) Air conditioner turned on (working pattern).

the outdoor conditions are comfortable, then the indoor environment can be improved through ventilation by opening the window. This is in contrast to other similar studies, in which the operation of related electrical appliances was mostly controlled to improve indoor environmental conditions. Regarding the four seasons of the year, it is most feasible to directly use automatic window ventilation to obtain good environmental quality in spring and fall. Simply automatically opening the window to obtain good living conditions rather than relying on electrical devices will save a lot of energy, which is an important novelty of this research. 


\section{Conclusions}

Through a literature review and data collection, factors contributing to a comfortable home environment were determined, as were their ranges of comfort. Moreover, the current applications of the IoT and smart buildings in the creation of comfortable home environments were examined. Directions for smart environmental control were proposed, and a prototype of a smart home environment control system was developed accordingly. Finally, the system functions were tested and verified. Specifically, simple sensing components connected to smart appliances - namely, an air conditioner, dehumidifier, air purifier, electronic window opener, and fan - through an Arduino control panel were used to collect data on temperature, humidity, $\mathrm{PM}_{2.5}, \mathrm{PM}_{10}$, and $\mathrm{CO}$ concentrations. Furthermore, software for controlling the appliances was developed with the purpose of creating a comfortable, convenient, and energy-efficient home environment. Establishing smart living spaces will help attain the goals of energy conservation and carbon reduction; this is beneficial for the future construction of green buildings and smart home environments. Future researchers can modularize the findings and work toward producing commercialized packages for smart building control to reduce development costs. In addition, the findings serve as a valuable reference for the development of smart, green buildings.

\section{References}

1 J. H. Seinfeld and S. N. Pandis: Atmospheric Chemistry and Physics: From Air Pollution to Climate Change (John Wiley \& Sons, Hoboken, New Jersey, USA, 2016).

2 B. Dong, V. Prakash, F. Feng, and Z. O’Neill: Energy Build. 199 (2019) 29. https://doi.org/10.1016/j. enbuild.2019.06.025

3 N. Naji, M. R. Abid, D. Benhaddou, and N. Krami: Information 11 (2020) 530. https://doi.org/10.3390/ infol1110530

4 R. Cantin, A. Kindinis, and P. Michel: Futures 44 (2012) 735. https://doi.org/10.1016/j.futures.2012.05.001

5 United Nations Environment Programme: Buildings and Climate Change: Summary for Decision-Makers (UNEP DTIESustainable Consumption \& Production Branch, Paris, France, 2009) pp. 1-62.

6 What Is Arduino?: https://www.arduino.cc/ (accessed February 2, 2021).

7 W.-L. Hsu, J.-Y. Jhuang, C.-S. Huang, C.-K. Liang, and Y.-C. Shiau: Appl. Sci. 9 (2019) 3520. https://doi. org/10.3390/app9173520

8 P. G. M. Boonekamp: Energy Econ. 29 (2007) 133. https://doi.org/10.1016/j.eneco.2005.09.010

9 L. Pérez-Lombard, J. Ortiz, and C. Pout: Energy Build. 40 (2008) 394. https://doi.org/10.1016/j. enbuild.2007.03.007

10 T. A. Nguyen and M. Aiello: Energy Build. 56 (2013) 244. https://doi.org/10.1016/j.enbuild.2012.09.005

11 E. Sheikhi, G. P. Cimellaro, and S. A. Mahin: Proc. European Workshop on Structural Health Monitoring, EWSHM 8 2016) 520-526.

12 W.-L. Hsu, W.-K. Wang, W.-H. Fan, Y.-C. Shiau, M.-L. Yang, and D. J. D. Lopez: Sens. Mater. 33 (2021) 269. https://doi.org/10.18494/SAM.2021.3164

13 M. P. Andersen, G. Fierro, S. Kumar, M. Chen, L. Truong, J. Kim, E. A. Arens, H. Zhang, P. Raftery, and D. E. Culler: Proc. 2nd ACM Int. Conf. Embedded Systems for Energy-Efficient Built Environments (2015) 121. https://doi.org/10.1145/2821650.2830312

14 A. S. Shah, H. Nasir, M. Fayaz, A. Lajis, and A. Shah: Information 10 (2019) 108. https://doi.org/10.3390/ info10030108

15 J. Gubbi, R. Buyya, S. Marusic, and M. Palaniswami: Future Gener. Comput. Syst. 29 (2013) 1645. https://doi. org/10.1016/j.future.2013.01.010

16 L. Cruz-Piris, D. Rivera, I. Marsa-Maestre, E. De la Hoz, and J. R. Velasco: Sensors 18 (2018). https://doi. org $/ 10.3390 / \mathrm{s} 18030917$

17 S. G. Navada, C. S. Adiga, and S. G. Kini: Int. J. Electr. Energy 1 (2013) 18. https://doi.org/10.12720/ ijoee.1.1.18-22 
18 J.-H. Choi: Indoor Built Environ. 26 (2017) 488. https://doi.org/10.1177/1420326X15626585

19 M. Jin, S. Liu, S. Schiavon, and C. Spanos: Build. Environ. 127 (2018) 268. https://doi.org/10.1016/j. buildenv.2017.11.003

20 R. M. Tetlow, C. P. Beaman, A. A. Elmualim, and K. Couling: Build. Environ. 81 (2014) 234. https://doi. org/10.1016/j.buildenv.2014.07.003

21 B. Dong, D. Yan, Z. Li, Y. Jin, X. Feng, and H. Fontenot: Build. Simul. 11 (2018) 899. https://doi.org/10.1007/ s12273-018-0452-X

22 C. Spataru and S. Gauthier: Archit. Eng. Des. Manage. 10 (2014) 60. https://doi.org/10.1080/17452007.2013.837 $\underline{248}$

23 W.-L. Hsu, W.-T. Chen, H.-H. Kuo, Y.-C. Shiau, T.-Y. Chern, S.-C. Lai, and W.-H. Fan: Sens. Mater. 32 (2020) 183. https://doi.org/10.18494/SAM.2020.2581

24 C.-C. Cheng and D. Lee: Sensors 14 (2014) 11179. https://doi.org/10.3390/s140611179

25 C.-C. Cheng and D. Lee: Sensors 16 (2016) 2028. https://doi.org/10.3390/s16122028

26 S. Y. Sim, M. J. Koh, K. M. Joo, S. Noh, S. Park, Y. H. Kim, and K. S. Park: Sensors 16 (2016) 420. https://doi. org/10.3390/s16040420

27 N. Li, G. Calis, and B. Becerik-Gerber: Autom. Constr. 24 (2012) 89. https://doi.org/10.1016/j. autcon.2012.02.013

28 Environmental Resource Information Open Platform / Air Quality Index: https://opendata.epa.gov.tw/Data/ Details/AQI/ (accessed 2 February 2021).

29 Mechanical Dehumidifiers and Related Components: (accessed 2 February 2021).

30 T. Qiu, N. Chen, K. Li, M. Atiquzzaman, and W. Zhao: IEEE Commun. Surv. Tutorials 20 (2018) 2011. https:// doi.org/10.1109/COMST.2018.2803740

31 H. Safa, W. El-Hajj, and H. Zoubian: J. Network Comput. Appl. 39 (2014) 70. https://doi.org/10.1016/j. jnca.2013.04.009

32 A. C. Santos, C. Duhamel, L. S. Belisário, and L. M. Guedes: J. Heuristics 18 (2012) 657. https://doi.org/10.1007/ s10732-012-9202-X

33 A. El-Mougy and M. Ibnkahla: Ad Hoc Networks 16 (2014) 46. https://doi.org/10.1016/j.adhoc.2013.11.013

$3438 \mathrm{kHz}$ Infrared Transmitter Module: https://www.taiwaniot.com.tw/ product $/ \% \mathrm{E} 7 \% \mathrm{~B} 4 \% 85 \% \mathrm{E} 5 \% \mathrm{~A} 4 \% 96 \% \mathrm{E} 7 \% \mathrm{~B} 7 \% 9 \mathrm{~A} \% \mathrm{E} 7 \% 99 \% \mathrm{BC} \% \mathrm{E} 5 \% \mathrm{~B} 0 \% 84 \% \mathrm{E} 6 \% \mathrm{~A} 8 \% \mathrm{~A} 1 \% \mathrm{E} 7 \% \mathrm{~B} 5 \% 84 /$ (accessed 2 February 2021).

35 Mq-7 Carbon Monoxide Sensor Detection Module: https://www.taiwaniot.com.tw/product/mq-7-\%E4\%B8\%80 \%Е6\%B0\%A7\%E5\%8C\%96\%Е7\%A2\%B3\%E6\%84\%9F\%E6\%B8\%AC\%Е5\%99\%A8\%E6\%A $\%$ A $1 \% \mathrm{E} 7$ $\% \mathrm{~B} 5 \% 84-\mathrm{co} \% \mathrm{E} 6 \% \mathrm{~B} 0 \% \mathrm{~A} 3 \% \mathrm{E} 9 \% \mathrm{AB} \% 94 \% \mathrm{E} 6 \% 84 \% 9 \mathrm{~F} \% \mathrm{E} 6 \% \mathrm{~B} 8 \% \mathrm{AC} \% \mathrm{E} 5 \% 99 \% \mathrm{~A} 8 /$ (accessed 2 February 2021).

36 Mg811 Co2 Carbon Dioxide Sensor Module: https://www.taiwaniot.com.tw/product $/ \mathrm{mg} 811-\mathrm{co2-} \% \mathrm{E} 4 \% \mathrm{BA} \% 8 \mathrm{C}$ $\% \mathrm{E} 6 \% \mathrm{~B} 0 \% \mathrm{~A} 7 \% \mathrm{E} 5 \% 8 \mathrm{C} \% 96 \% \mathrm{E} 7 \% \mathrm{~A} 2 \% \mathrm{~B} 3 \% \mathrm{E} 6 \% 84 \% 9 \mathrm{~F} \% \mathrm{E} 6 \% \mathrm{~B} 8 \% \mathrm{AC} \% \mathrm{E} 5 \% 99 \% \mathrm{~A} 8 \% \mathrm{E} 6 \% \mathrm{~A} 8 \% \mathrm{~A} 1 \% \mathrm{E} 7$ \%B5\%84-mg811-\%Е9\%9B\%BB\%E5\%A3\%93\%E5\%9E\%8B-0-2v-\%E9\%9B\%BB $\%$ E5\%A3\%93\%Е8\%BC $\%$ B

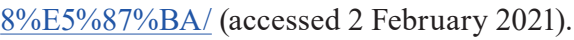

37 Am2320 Digital Temperature and Humidity Sensor Probe: https:/www.taiwaniot.com.tw/product/aosongam2320-digital-temperature-humidity-sensor/ (accessed 2 February 2021). 